\title{
Editorial
}

\section{Helmut Gründl}

Chair for Insurance and Regulation, International Center for Insurance Regulation, Goethe University, Frankfurt, Germany.

E-mail: gruendl@finance.uni-frankfurt.de

The Geneva Papers (2018) 43, 591-593. https://doi.org/10.1057/s41288-018-0092-5; published online 21 August 2018

Insurance regulation is entering an important phase worldwide. Over the past two decades, risk-based microprudential solvency regulation has been introduced in many economic areas, and the experience being gained with this regulation today will provide input for future improvements. First and foremost, any improvements must be based on a thorough analysis of the impact of the present systems on consumers, the insurance industry, the insurance markets, (cross-border) insurance supervision, and financial stability as a whole. Subsequent action will comprise straightforward amendments to the present rules, recovery and resolution arrangements, control of the interplay between micro- and macroprudential regulation, and aligning banking and insurance regulation to avoid regulatory arbitrage.

Besides solvency regulation, consumer protection is currently the second most important topic in insurance regulation. However, regulating products and distribution channels requires a profound cost-benefit analysis because it is the consumer who ultimately bears most of the cost of consumer protection. In addition, we need to take into account the fact that consumer protection, e.g. in the form of granting extensive contract termination rights in life insurance, can also influence an insurer's solvency situation. In this way, consumer protection and solvency regulation are strongly linked.

Insurance companies and insurance markets are affected not only by direct insurance regulation but also by general cross-sectoral regulatory projects such as the introduction of "International Financial Reporting Standards" (IFRS). These regulatory projects can, for example, influence the transparency of insurance companies and their products, and are therefore an important factor to consider when discussing insurance regulation.

This special issue of The Geneva Papers on "Insurance and Regulation", comprising six articles on economic and legal aspects, can cover only some of the above-mentioned topics. Three articles deal with solvency regulation, one article looks at the impact of the IFRS on European insurers, and two articles discuss the impact of implementing the "Insurance Distribution Directive" (IDD) as well as the possibility of applying its rules beyond the European Union.

In their article "Cross-Border Insurance Groups: Towards a Comprehensive Supervision Under Solvency II", Pierpaolo Marano and Michele Siri analyse how cross-border group supervision is organised under Solvency II. In effect, we can observe a sophisticated and finely tuned interplay between national supervisory authorities and the European Insurance and Occupational Pensions Authority (EIOPA), which also reflects general political 
interaction in the European Union. Marano and Siri make a plea for extending the tasks of the colleges of supervisors: they should define and implement a common principle of "group interest" for controlling and improving the system of governance of cross-border insurance groups. Furthermore, they suggest that the colleges should also supervise the distribution of insurance products.

Derrick W. H. Fung, David Jou, Ai Ju Shao, and Jason J. H. Yeh analyse "The Implications of the China Risk-Oriented Solvency System on the Life Insurance Market". Like Solvency II, the China Risk-Oriented Solvency System (C-ROSS) came into force fully in 2016. The two regulatory systems share quite a few commonalities, for example a very similar three-pillar approach. The empirical work by Fung et al. is an early impact study on the effects of the newly introduced Chinese insurance regulation on the life insurance industry. The reported results show in principle a positive effect of C-ROSS on life insurers' solvency situation, but also expose a vulnerability to low interest rates. Certainly, the study will also serve as a benchmark for further impact studies concerning the introduction of Solvency II and other risk-based regulatory systems.

Throughout the development of the Solvency II rules, the standard formula for determining the solvency capital requirement was criticised for not adequately mapping specific economic risks. To some extent, these complaints are a consequence of the very nature of the standard formula: in mapping a standard situation, it inevitably misses the mark for a specific setting. Over the years, changing the standard formula towards mapping (country-) specific circumstances has in fact made it a very complicated and partly opaque instrument. However, there must always be room for improving the standard formula. This is the starting point for Laurens Swinkels, David Blitz, Winfried Hallerbach, and Pim van Vliet. In their article "Equity Solvency Capital Requirements: What Institutional Regulation Can Learn from Private Investor Regulation", they suggest transferring rules for European retail investors to the insurance area, and basing insurers' capital charges on these rules-without doubt an interesting idea for the Solvency II review process.

For capital market-oriented insurers, the period of preparing for Solvency II in the European Union coincided with the introduction of financial reporting based on the "International Financial Reporting Standards" (IFRS). Initially, there was great hope of synergy effects between the IFRS and Solvency II, especially regarding the valuation standards for assets and liabilities. However, this hope could only be partially fulfilled. Another hope was that the increase in transparency through IFRS would be rewarded by capital market participants and would therefore lead to better stock performance of insurers. By applying event study techniques, Abed Al-Nasser Abdallah, Wissam Abdallah, and Feras M. Salama investigate "The Market Reaction to the Adoption of IFRS in the European Insurance Industry". They find an overall positive reaction of the capital markets to the adoption of IFRS in European countries-more pronounced for non-life than for life insurers.

For decades, insurance distribution has been a major source of consumer complaints and consequently a source of reputational risk for insurance companies. To overcome these issues, the "Insurance Distribution Directive" (IDD) attempts to strengthen consumer protection in the European Union by defining minimum advice quality and setting transparency standards. Thus, the development of the IDD has been a major regulatory endeavour in the European Union over the past few years, parallel to the introduction of Solvency II. In their article "The New Insurance Distribution Regulation in the EU-a 
Critical Assessment from a Legal and Economic Perspective", Thomas Köhne and Christoph Brömmelmeyer give an economic and legal evaluation of the IDD and find that "the IDD appears to be associated with over-regulation in some areas". Annette Hofmann, Julia K. Neumann, and David Pooser in their contribution "Plea for Uniform Regulation and Challenges of Implementing the New Insurance Distribution Directive" elaborate on the challenges of the IDD implementation in selected countries of the European Union, and they discuss how far the IDD could serve as a basis for insurance distribution regulation in the United States.

All articles published in this special issue contribute to the ongoing discussion on improving insurance regulation with the aim of fostering insurer safety, consumer protection and financial stability. The articles provide many valuable insights into regulatory effects and can therefore serve as important guides on the road towards a competitive but at the same time safe and fair financial system.

It has been a great honour to edit this special issue of "The Geneva Papers on Risk and Insurance-Issues and Practice". However, serving as guest editor was only made possible with many helping hands throughout the past year. I would like to express my special thanks to Christophe Courbage, Sandra Postle, and Frederick Schlagenhaft from The Geneva Association for their invaluable support. I would also like to thank all our referees who spent many hours helping to assess and improve the articles. Their service to the scientific community demands the greatest possible respect and gratitude. It only remains for me to wish you much pleasure in reading this special issue on "Insurance and Regulation". 